\title{
The Researches on Reasonable Well Spacing of Gas Wells in Deep and low Permeability Gas Reservoirs
}

\author{
$Y u$ Bei Bei ${ }^{1{ }^{1 *}}, L i$ Hui $^{1}$, and $L i$ Dong $\operatorname{Lin}^{2}$ \\ ${ }^{1}$ Exploration and Development Research Institute of Dagang Oilfield, Binhai New area,Tianjin300280, China \\ ${ }^{2}$ Oil \& Gas Cooperation And Development Company, BHDC, Binhai New area,Tianjin300280, China
}

\begin{abstract}
This Gs64 gas reservoir is a condensate gas reservoir which is relatively integrated with low porosity and low permeability found in Dagang Oilfield in recent years. The condensate content is as high as $610 \mathrm{~g} / \mathrm{m} 3$. At present, there are few reports about the well spacing of similar gas reservoirs at home and abroad. Therefore, determining the reasonable well spacing of the gas reservoir is important for ensuring the optimal development effect and economic benefit of the gas field development. This paper discusses the reasonable well spacing of the deep and low permeability gas reservoir from the aspects of percolation mechanics, gas reservoir engineering and numerical simulation. considering there exist the start-up pressure gradient in percolation process of low permeability gas reservoir, this paper combined with productivity equation under starting pressure gradient, established the formula of gas well spacing with the formation pressure and start-up pressure gradient. The calculation formula of starting pressure gradient and well spacing of gas wells. Adopting various methods to calculate values of gas reservoir spacing are close to well testing' radius, so the calculation method is reliable, which is very important for the determination of reasonable well spacing in low permeability gas reservoirs.
\end{abstract}

\section{Introduction}

The determination of well spacing in low permeability gas reservoirs is the key parameter for its economic and reasonable development. Due to the small pore throat, poor pore connectivity, there are low permeability and high water saturation in low permeability gas reservoirs, Gas percolation is easy to represent unique percolation characteristics which is different from that of medium and high permeability gas reservoirs [1]. In low permeability reservoirs, gas percolation far away from bottom hole area appears low speed non-Darcy percolation, and how long distance away from bottom hole the gas can overcome starting pressure gradient to flow, that is the gas well spacing which we need to calculate. Many experts and scholars have their own opinions on the calculation method of well spacing. Li Shuang [2], Wang Xiuzhi [3] and others did not consider the influence of starting pressure gradient, and adopted economic limit control reserve method, single well area method and numerical simulation method to discuss the reasonable well spacing of low permeability gas reservoir. Although Guoqi [4] considered the influence of starting pressure gradient, deduced the formula for calculating reasonable well spacing of low permeability gas reservoir, but the calculation parameters are too many and the calculation is complicated. In this paper, starting from low speed non-Darcy seepage flow and combining with single well productivity equation, the control radius of single well considering starting pressure gradient is derived, combined with various methods of gas reservoir engineering and numerical simulation, The reasonable well spacing of low permeability gas reservoir is determined synthetically, the calculation is simple and the result is reliable.

\section{Geological characteristics}

The Gs64 block is located in the southern of Tangjiahe Oilfield, the descending plate of the gangdong fault. The main layers is Ban2 and Ban3 which are Low porosity and low permeability sandstone reservoir, reservoir depth is between $4200 \mathrm{~m}$ and $4400 \mathrm{~m}$, the porosity is range from $11.5 \%$ to $17.2 \%$, the permeability is range from $3.7 \times 10^{-3} \mu \mathrm{m}^{2}$ to $10.27 \times 10^{-3} \mu \mathrm{m}^{2}$. The reservoir is in deep lake environment, with wide distribution, large thickness, deep burial, poor physical properties, low production degree and great difficulty in development.

\section{Reasonable well spacing determination method}

\subsection{Seepage mechanics method}

Domestic scholars' researches show that [5-7] the intact percolation of low permeability reservoir should be as shown in Figure 1: section I represents the low speed non-Darcy segment affected by the starting pressure gradient and threshold pressure effect, II represents the

\footnotetext{
*Yu Beibei: yu_beibei@,foxmail.com
} 
Darcy percolation stage; III means the high-speed nonDarcy stage under high yield conditions.

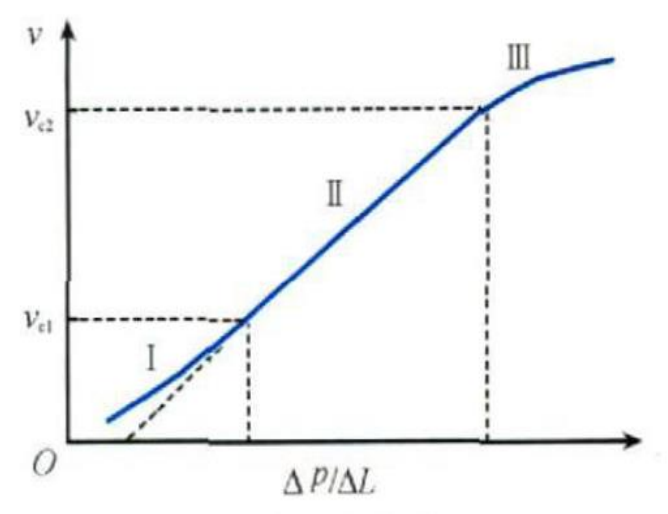

Fig. 1 Nonlinear percolation characteristic map of low permeability gas reservoir

When there is a starting pressure gradient, the linear relation with the origin between $\mathrm{v}$ and $\Delta \mathrm{P} / \Delta \mathrm{L}$ is not exist. Considering the starting pressure gradient, the equation which considered the starting pressure gradient in low velocity non-Darcy gas seepage flow is as follows:

$$
\left\{\begin{array}{cc}
v=0 & \left(\operatorname{grad} p \leq \lambda_{B}\right) \\
v=\frac{\mathrm{K}}{\mu}(\operatorname{grad} p-\lambda) & \left(\operatorname{grad} p>\lambda_{B}\right)
\end{array}\right.
$$

The meaning represented by symbols in a formula:

$v$ : velocity of gas movement in reservoir, $\mathrm{m} / \mathrm{s}$;

$\mu$ : gas viscosity, mPa.s;

$\mathrm{k}$ : absolute permeability, $10^{-3} \mu \mathrm{m}^{2}$;

gradp: pressure gradient, $\mathrm{MPa} / \mathrm{m}$;

$\lambda$ : starting pressure gradient, $\mathrm{MPa} / \mathrm{m}$.

The horizontal radial flow velocity of gas in the reservoir at $r$ distance from the bottom of the well can be expressed by the underground flow rate:

$$
v=\frac{\mathrm{Q}}{2 \pi \mathrm{rh}}
$$

The meaning represented by symbols in a formula:

Q: Underground flow in reservoir, $\mathrm{m}^{3} / \mathrm{s}$;

$\mathrm{h}$ : Reservoir thickness, $\mathrm{m}$.

By using the equation of state, the velocity of gas flow can be expressed as the relation of surface production.

$$
v=\frac{1}{2 \pi r h} \frac{P_{S C} Z T}{Z_{S C} T_{S C} P_{e}} Q_{S C}
$$

The meaning represented by symbols in a formula:

$Q_{s c}$ : single well surface production, $\mathrm{m}^{3} / \mathrm{s}$;

$\mathrm{T}_{\mathrm{sc}}$ : temperature in the standard state, $\mathrm{K}$;

$\mathrm{Z}_{\mathrm{sc}}$ : deviation factor in the standard state;

$\mathrm{T}$ : formation temperature, $\mathrm{K}$;

$\mathrm{Z}$ : deviation factor;

$\mathrm{P}_{\mathrm{sc}}$ : pressure in the standard state, $\mathrm{MPa}$;

$\mathrm{P}_{\mathrm{e}}$ : current formation pressure, $\mathrm{MPa}$.

According to formula (1), when the pressure gradient of the resultant force of the gas at half of the well distance $r$ is greater than the starting pressure gradient, the flow velocity of the gas is greater than 0 , then the gas can flow. The formula of gas flow conditions at $r$ can be obtained by combining the three equations (1) (2) and (3).

$$
\frac{\mu}{K} \frac{1}{2 \pi r h} \frac{P_{S c} Z T}{Z_{S c} T_{S c} P_{e}} Q_{S C} \geq 0
$$

Yihuaijian etc. [8] considering starting pressure gradient got the production equation formula.

$$
Q_{S C}=\frac{\pi K h Z_{s c} T_{S C}\left[P_{e}^{2}-P_{w f}^{2}-2 \lambda P_{e}\left(r-r_{w}\right)\right]}{\mu Z T P_{s c} \ln \frac{r}{r_{w}}}
$$

The meaning represented by symbols in a formula:

$\mathrm{P}_{\mathrm{wf}}$ : flowing pressure of bottom hole, $\mathrm{MPa}$;

The control radius of a gas well can be obtained by taking formula (5) into formula(4)

$$
r \leq \frac{P^{2} e^{-P^{2}}{ }_{w f}}{2 P_{e} \lambda}+r_{w}
$$

According to this formula, the control radius of gas well can be calculated by only knowing the formation pressure of gas reservoir, the flowing pressure of bottom hole and the starting pressure gradient of reservoir, and then the well spacing of gas reservoir can be obtained.

The original formation pressure of the Gs64 gas reservoir is $50.37 \mathrm{MPa}$. the reasonable production pressure differential is $13 \mathrm{MPa}$. the wellbore radius is $0.1 \mathrm{~m}$. the starting pressure gradient is $0.04 \mathrm{MPa} / \mathrm{m}$. taking these parameters into the formula(6) to calculate the control radius of single well is $283 \mathrm{~m}$, so the well spacing is $566 \mathrm{~m}$.

\subsection{Gas reservoir engineering method}

Only one well gs64 has been produced in GS64 gas reservoir, and the production is long and continuous. Therefore, the production dates of this well can be used to the decline curve analysis and the single well control reserves estimating, thus the control radius is obtained. Because the analytical method of decline curve is an empirical observation result of the well's production history, so the decline curve analysis is applicable in any case, mainly refers to the case of a single fluid or multiple fluids.

Using Blasingame Type curve Analysis method to fit the production data, figure 2 , we calculate the well control reserves is $0.64 \times 10^{8} \mathrm{~m}^{3}$, the control area is $0.26 \times \mathrm{km}^{2}$, the radius is $290 \mathrm{~m}$, and the well spacing is $580 \mathrm{~m}$.

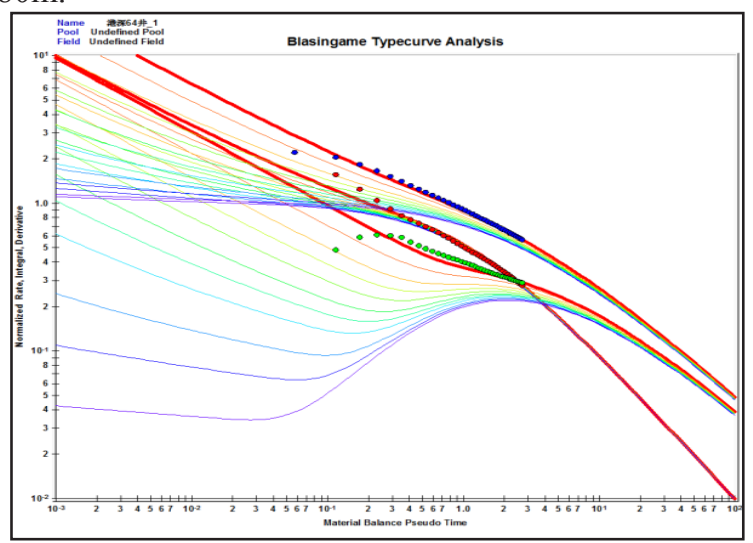

Fig. 2 Blasingame type curve analysis of well GS64

\section{Comparative study on different well spacing schemes}


According to the data of well spacing calculated by the former two methods, we designed three sets of well spacing schemes of $400-500 \mathrm{~m}, 500-600 \mathrm{~m}$ and $600-$ $800 \mathrm{~m}$ to predict and compare the project indexes.

\subsection{Geological modeling and historical fitting}

The geological model of gs64 fault block is established by using Petrol modeling software. The three dimensional geological modeling layer is Ban2, Ban3 oil group. The simulation flat grid step size is $25 \mathrm{~m} \times$ $25 \mathrm{~m}$, vertical grid step size is $0.5 \mathrm{~m}$, total grid number are $173 \times 141 \times 225=5488425$.

After the reserve fitting of the model, according to the actual data, we conducting the historical fitting about the pressure of the whole area and the single well production index, the permeability, pressuresensitive parameters and permeability data of the gas reservoir are mainly adjusted. At the same time, considering the damage of drilling and operation to gas well productivity, the well point permeability and skin coefficient of gas well are corrected. The fitting rate of production index is more than $95 \%$, which meets the standard of simulation and the model meets the requirement of project prediction.

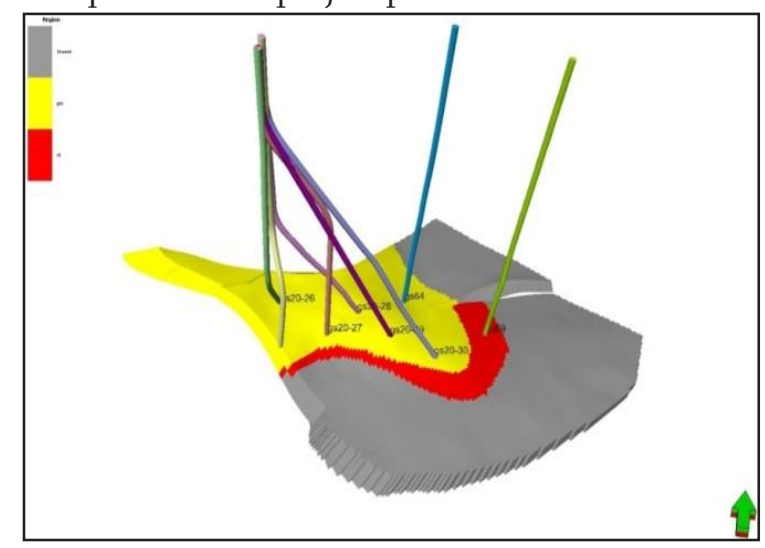

Fig. 3 Hydrocarbon model of GS64 reservoir

\subsection{Comparison of different well spacing schemes}

From the prediction results and curves of the three well spacing scheme indexes (Table 1, figure 4, figure 5 ), it can be seen that the oil and gas cumulative production of case one is close to that of case two, which are higher than that of case 3 , in order to improve the efficiency of development, It is recommended that the case two with a fewer wells is the optimal scheme, and the optimum well spacing is between $500 \mathrm{~m}$ and $600 \mathrm{~m}$.

The GS64 well has been done systematic well testing by using a high precision direct reading electronic pressure gauge. The well testing radius is $311 \mathrm{~m}$, so the well spacing calculated by the well testing is around $600 \mathrm{~m}$, which are close to the results calculated by Seepage mechanics method. It means the Seepage mechanics method which be deduced to calculate the well spacing is reliable, and the well spacing of the gas reservoir is about $600 \mathrm{~m}$. It accords with the production knowledge of low permeability gas reservoir.

Table 1 Forecast results of three program indicators

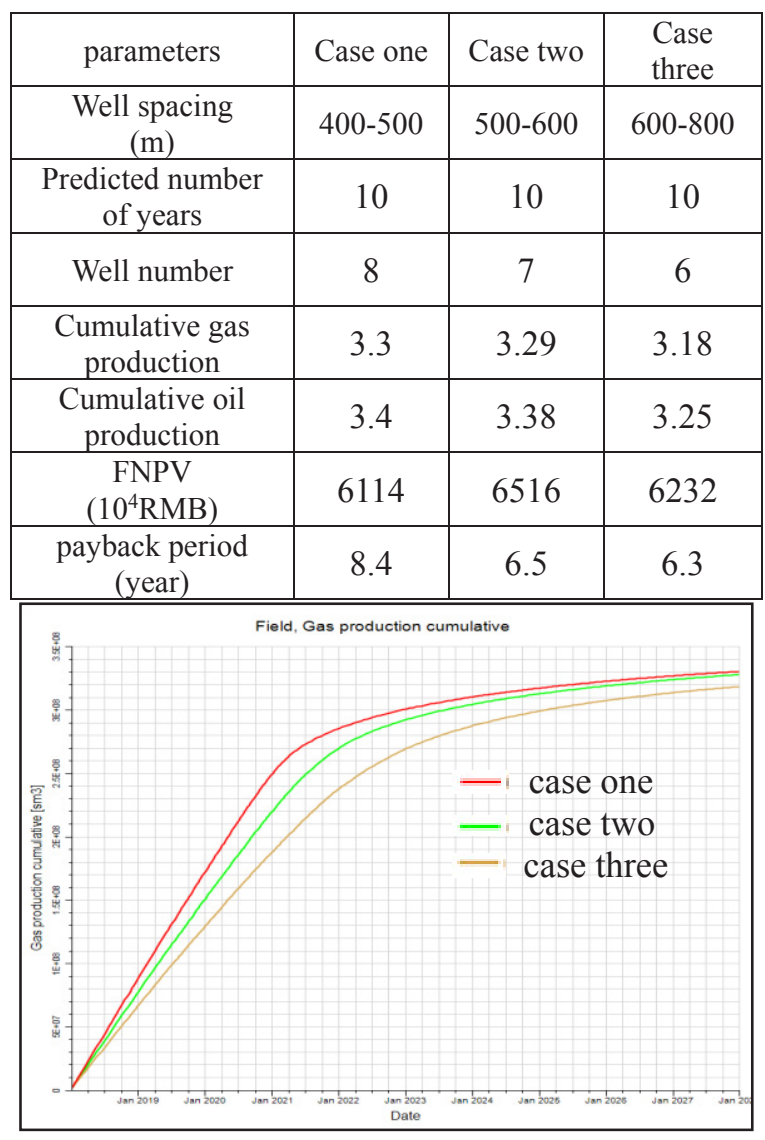

Fig. 4 Comparison of cumulative gas production of different schemes

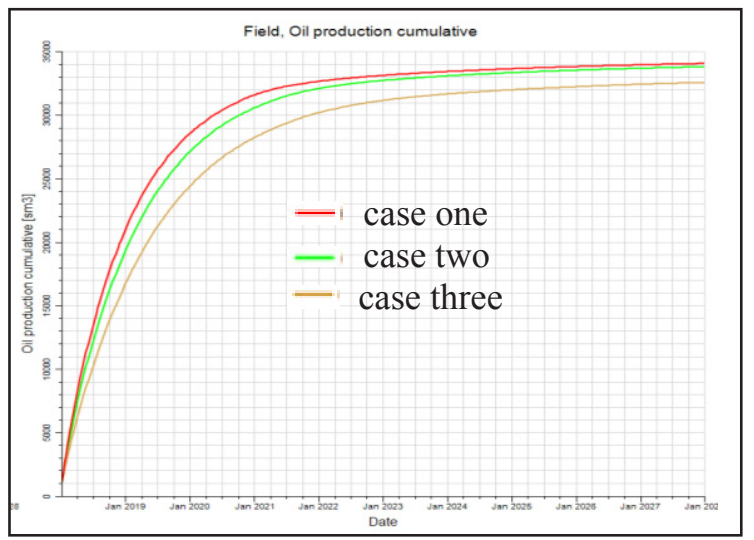

Fig. 5 Comparison of cumulative oil production of different schemes

\section{Conclusion}


(1) The determination of reasonable well spacing of low permeability gas reservoir is the key to ensure its reasonable and efficient development. According to its percolation characteristics, the influence of starting pressure gradient should be considered, and a variety of methods should be adopted to study and determine comprehensively.

(2) According to the flow conditions of reservoir fluid, the calculation method of reasonable well spacing for gas wells in low permeability gas fields is deduced in this paper. The calculation formula involves less parameters and is simple and convenient to calculate. The calculated results are compared with the well spacing calculated by well testing, The results of the new method are reasonable and can be used as a reference for well distribution in low permeability gas reservoirs.

(3) Through numerical simulation, the well spacing of GS64 low permeability gas reservoir is optimized, ranging from $500 \mathrm{~m}$ to $600 \mathrm{~m}$, which accords with the understanding of low permeability gas reservoir development.

\section{References}

1. Feng Wenguang. Non-Darcy Low-velocity Unsteady-State Seepage Flow of Natural Gas. J. Natural Gas Industry, 1986,6(3): 41-48

2. Li Shuang, Zhou Xinjia, Jin Hui, Jing Yuanshuai. Study on Rational Well Pattern and Well Spacing in Low Permeability Gas Field. J. Special Oil\&Gas Reservoirs,2010, 17(5): 73-75

3. Wang Xiuzhi, Shi Zhiliang. Study on Economic and Reasonable Well Spacing of Changxing Formation Reservoir Development in Yuanba Gas Field. J. Fault-Block Oil\&Gas Field 2012, 19(3): 340-342

4. Guo Qi, Li Zhen, Chen Kaiyuan. Well Spacing Optimization of Vertical Well in LowPermeability Gas Reservoir. J. Special Oil\&Gas Reservoirs 2016,23(4):109-111.

5. Zhou Keming, Li Ning, Yuan Xiaoling: Gas Percolation Mechanism of Low Permeability Reservoirs With Low Speed Under Residual Water Conditions. J. Special Oil\&Gas Reservoirs, 2016,23(4):109-111

6. Wu Fan, Sun Lijuan, Qiao Guo'an. A Research on Gas Flow Property and Starting Pressure Phenomenon. J. Natural Gas Industry, 2001,21(1):82-84

7. Liu Xiaoxu, Hu Yong, Li Ning, Zhu Bin. Experimental Study and Analysis of the Special
Percolation Mechanism in Low Permeability Sandstone Gas Reservoir. J. Special Oil\&Gas Reservoirs 2007,14(1):80-83.

8. Yi Huaijian, Zhu Weiyao, Zhang Mingjiang. Analysis of Formation Pressure Distribution and Productivity of Low Permeability Tight Gas Reservoirs With Low-Velocity Non-Darcy Flow. J. Special Oil\&Gas Reservoirs, 2012,19(1):70-73. 